\title{
Obtaining a Flexible Film Elaborated from Cassava Thermoplastic Starch and Polylactic Acid
}

\author{
Germán A. Arboleda, ${ }^{1}$ Camilo E. Montilla, ${ }^{1}$ Héctor S. Villada, ${ }^{2}$ and Giovanni A. Varona ${ }^{1}$ \\ ${ }^{1}$ Grupo de Investigación Ciencia y Tecnología de Biomoléculas de Interés Agroindustrial, (CYTBIA), Popayán, Colombia \\ ${ }^{2}$ Departamento de Agroindustria, Universidad del Cauca, Popayán, Colombia \\ Correspondence should be addressed to Germán A. Arboleda; ganar215@hotmail.com
}

Received 8 May 2015; Revised 18 July 2015; Accepted 21 July 2015

Academic Editor: Mukund Adsul

Copyright (C) 2015 Germán A. Arboleda et al. This is an open access article distributed under the Creative Commons Attribution License, which permits unrestricted use, distribution, and reproduction in any medium, provided the original work is properly cited.

\begin{abstract}
A flexible film was obtained from a blend of cassava thermoplastic starch and polylactic acid, using maleic anhydride as coupling agent. For this, an experimental design with three factors was used: polylactic acid content, coupling agent content, and temperature profile of the blown extrusion. It was found that the three factors generated significant differences on the response variables of tensile mechanical properties individually as in their triple interaction. Differential scanning calorimetry (DSC) was used by understanding the behavior of thermal properties of TPS/PLA blends with and without coupling agent, finding similar results between both. From this, the combination with $28 \%$ polylactic acid, $0.87 \%$ coupling agent, and $155.75^{\circ} \mathrm{C}$ temperature profile permitted the obtaining of a material with outstanding mechanical properties and offered advantages from the economic point of view.
\end{abstract}

\section{Introduction}

The global production of plastics is estimated at 300 million tons for 2015, being a serious environmental problem due to the slow degradation in nature of these materials produced from nonrenewable sources like petroleum, carbon, and natural gas [1], a situation that has triggered the development of new products from raw materials based on renewable sources, where biopolymers appear as the best alternative to petroleum-based polymers.

These bioplastics represent a broad spectrum of thermoplastic materials obtained from biological resources, fossils, or combinations of these [2] and they are generating growing interest in general society, plastics industry, and agricultural sector, given that it would suppose the exposure of its products to different markets [3]. In this order of ideas, starch, which is a storage polysaccharide in plants [2], is a widely used bioplastic because it is cheap, abundantly produced, and available in many renewable sources [4]. It has high potential for use in the synthesis of biodegradable materials [3] for which it is used as a thermoplastic material obtained through the interruption of its molecular interactions using plasticizers under specific conditions [2], achieving thermoplastic starch (TPS). However, they present disadvantages like their high solubility in water, hygroscopicity, and rapid aging due to retrogradation and low mechanical properties, limiting some of their applications [3]. Although these inconveniences can be reduced by mixing with other polymers [5] like polycaprolactone (PCL) [6], polylactic acid (PLA) [7], PLA/PCL binary blends [8], polyvinyl alcohol [9], and polyhydroxybutyrate [9], among others.

Of these, PLA stands out especially because of its properties, by being a renewable, biocompatible, and biodegradable polymer. It is one of the widely used bioplastics [2], so much so that in 2012 it was along with starch, the two commercial biodegradable polymers of highest importance, representing close to 47 and $41 \%$, respectively, of the total consumption of biodegradable polymers [10]. It is obtained from renewable resources like corn, beets, wheat, and other products rich in starch [11] whose fermentation generates lactic acid polymerization, originated by the opening of the cyclic dimer ring [12]. It has higher stability of the melted mass, although its films are fragile due to the high crystallinity and level of physical aging.

However, the principal inconvenience presented by these types of blends is their immiscible phases due to the lack of 
affinity between the hydroxyl groups and carboxyl terminals of hydrophobic PLA and hydroxyl groups of hydrophilic TPS [12]; additionally, it has been found that the mechanical properties of these blends diminish as TPS content increases, thus, limiting TPS content in said blends [5]. To increase compatibility among the phases, different coupling agents have been used like citric acid [13], formamide [14], and especially maleic anhydride [15] as compatibilizing agent. One advantage of using anhydrides, and in this particular case, maleic anhydride, is that it does not generate byproducts when the change is made, since it is only a reaction ring opening [16]. Additionally, small amounts should be used, which reduces the costs of the final film.

This research studied the possibility of obtaining a material constituted by thermoplastic starch (TPS) from cassava and polylactic acid grafted with maleic anhydride to evaluate its mechanical and thermal properties to, thus, determine the combination of polylactic acid content, coupling agent, and temperature profile of the blown extrusion that would offer the highest characteristics regarding tensile properties.

\section{Materials and Methods}

This research was developed in the Rheology and Packages Laboratory at Universidad del Cauca (Popayán, Colombia).

2.1. Materials. Thermoplastic starch was obtained from cassava starch (Almidones de Sucre, Colombia). To produce polylactic acid, PLA reference 4032D (Cargill Dow Polymers LLC) was used. Some of the additives used included glycerin (99.5\% purity, Disan S.A.) as plasticizer, maleic anhydride (99.0\% purity, Merck) as coupling agent, benzoyl peroxide (reagent grade, Merck) as indicator agent, and stearic acid (99.3\% purity, Merck) as TPS extrusion adjuvant.

2.2. Processing. To obtain TPS, the starch was first dried in a forced convection oven (Memmert) at $60^{\circ} \mathrm{C}$ for $15 \mathrm{~h}$, and then the dry starch was mixed with glycerol at a $70: 30$ starch/glycerol ratio and $0.5 \%$ of stearic acid, for $10 \mathrm{~min}$ by using a high-speed blender (Kitchen Aid, model K45SS, USA). The blend was stored in a polypropylene sealed container for $48 \mathrm{~h}$. After this time, the starch was thermoplasticized in a single-screw extruder (Thermo Scientific, model Haake Polylab OS, Germany) equipped with a $19 \mathrm{~mm}$ diameter barrel, a screw with a $5: 1$ compression ratio, and an $L / D$ ratio of 25 . A strand die was used along with a nozzle with $1 \mathrm{~mm}$ diameter opening. The TPS strand was gathered, dried at $80^{\circ} \mathrm{C}$ for $1 \mathrm{~h}$, and pelletized to finally be packed in a sealed container. This extrusion used a screw rate of $50 \mathrm{rpm}$ and a temperature profile of $112.25^{\circ} \mathrm{C}$.

Thereafter, the grafted polylactic acid $4032 \mathrm{D}$ was processed, experimenting with three concentrations of maleic anhydride $0.5,0.87$, and $1.23 \%$ based on the weight of the polylactic acid. Prior to this, the polylactic acid was dried for $4 \mathrm{~h}$ at $80^{\circ} \mathrm{C}$, by following manufacturer's specifications. Extrusion conditions for the grafted PLA were temperature of $177.50^{\circ} \mathrm{C}$ and $30 \mathrm{rpm}$ screw rate, obtained from preliminary tests, as well as a strand nozzle with $1 \mathrm{~mm}$ opening.
Lastly, the TPS and grafted PLA blend was carried out in proportions of 22, 25, and $28 \%$ of PLA. This was processed under three different temperature profiles: $153.30,155.75$, and $158.00^{\circ} \mathrm{C}$, in a single-screw extruder at a $35 \mathrm{rpm}$ rate, using a blow die with a $70 \mu \mathrm{m}$ opening and a set of rollers to standardize the thickness of the flexible film.

2.3. Evaluation of Tensile Mechanical Properties. The tensile mechanical properties of the flexible films obtained were measured: elastic modulus ( $\mathrm{MPa})$, maximum tensile strength $(\mathrm{MPa})$, and maximum elongation (\%). The samples were taken to a temperature chamber (Binder, model KBF 115), where they were stored under constant relative humidity conditions $(50 \pm 10 \%)$ and temperature $\left(23 \pm 2^{\circ} \mathrm{C}\right)$ for 8 days. Universal test equipment was used (Shimadzu model EZ-L) following the ASTM D882-10 standard [17], which establishes the procedure to execute the tensile test on films. The following operating conditions were taken: a $500 \mathrm{~N}$ cell, $25 \mathrm{~mm} / \mathrm{min}$ spindle speed, data collection rate of 500 points/s, and $50 \mathrm{~mm}$ distance between vises. Samples were cut in longitudinal and transversal directions with dimensions of $90 \mathrm{~mm}$ length by $20 \mathrm{~mm}$ width. Sample thicknesses were taken by using a micrometer (Testing Machine, Inc., model 549).

2.4. Differential Scanning Calorimetry (DSC). This was conducted according to that established in the ASTM D341808 standard by using a TA Instruments calorimeter (model Q20, USA). The samples of the films of approximately $10 \mathrm{mg}$ were previously conditioned for an 8-day period at $23 \pm$ $2^{\circ} \mathrm{C}$ and $50 \pm 10 \% \mathrm{RH}$. The sample was deposited into an aluminum capsule, sealed, and placed in the calorimeter's thermal chamber. A first heating cycle was conducted from ambient temperature to $190^{\circ} \mathrm{C}$ to erase the thermal history at a heating rate of $10^{\circ} \mathrm{C} / \mathrm{min}$, followed by an isotherm of $190^{\circ} \mathrm{C}$ for $5 \mathrm{~min}$. Thereafter, a cooling cycle was carried out from $190^{\circ} \mathrm{C}$ to $-80^{\circ} \mathrm{C}$ at a cooling rate of $20^{\circ} \mathrm{C} / \mathrm{min}$ and an isotherm of $-80^{\circ} \mathrm{C}$ for $5 \mathrm{~min}$. Finally, a heating cycle was conducted from -80 to $200^{\circ} \mathrm{C}$ to determine the glass transition temperature $\left(T_{g}\right)$, crystallization temperature $\left(T_{c}\right)$, and melting temperature $\left(T_{m}\right)$ in the respective samples.

2.5. Statistical Analysis. An analysis of variance (ANOVA) was performed to establish significant differences among treatments $(P<0.05)$, employing Tukey and T3 tests by Dunnett; SPSS software was used (version 21.0 for Windows). The analysis verified the normality assumptions of the samples by using the Shapiro-Wilk test, as well as the presence or lack of homogeneity of variance through Levene's test, all with a significance value of 0.05 . For the comparison of the two treatments, Student's $t$-test was used.

\section{Results and Discussion}

3.1. Tensile Mechanical Properties. According to the experimental design, 27 factor combinations were obtained: polylactic acid content, coupling agent, and temperature profile of blown extrusion; each of these with the three response 
variables was employed in the study. This was done to determine the formulation with which the highest indices of tensile mechanical properties were obtained. First, these were subjected to a Shapiro-Wilk test, proving that the samples, both in longitudinal and transversal direction, were extracted from populations with normal probability distribution, a necessary condition for a reliable study of variance. After determining the normal condition of the data, an ANOVA was conducted in both directions, finding that the totality of the response variables was influenced by the three factors evaluated and by their interactions, both double (AA-PLA, AA-temperature, and PLA-temperature) and triple (AA-PLA-temperature), which demonstrated that the result generated by the different factors was not present in isolated manner but that the effect was influenced by the other two. In this sense, it was determined which of the treatments with the AA, PLA content combination and temperature profile yielded outstanding mechanical properties.

An ANOVA test was used, finding that at least two treatments presented statistic differences in the three response variables. Upon this finding, the Levene variance homogeneity test was executed; from this test, it was found that, both in longitudinal and transversal directions, for the three response variables, the postulate of variance homogeneity was not fulfilled, which is why Dunnett's T3 multiple comparisons were performed.

Dunnett's T3 test yielded different results. In longitudinal direction, treatment 26 had the highest elastic modulus values and maximum tensile strength, while treatment 20 stood out with the maximum elongation at the rupture point, although both belonged to the same subgroup. Also, in the transversal direction, treatment 17 showed the highest values of elastic modulus; in spite of not presenting outstanding indicators regarding maximum tensile strength, it was not significantly different from the higher value treatment (treatment 16). With respect to the maximum elongation at the rupture point, treatment 19 stood out. Table 1 shows the results obtained regarding tensile mechanical properties in longitudinal and transversal directions for each of the 27 treatments obtained during the experimental design.

The PLA content was the factor with the highest influence upon the response variables: elastic modulus and tensile strength in longitudinal direction, which evidenced a tendency to find higher values of these properties as PLA content was increased. An average 28\% PLA content obtained indices of $279.48 \mathrm{MPa}$ in the elastic modulus, $77.7 \%$ above that found in the treatment with lower value, while, at this level, the maximum tensile strength showed an average of $4.97 \mathrm{MPa}$, representing a $33.3 \%$ increase with respect to the lower level, as evidenced in Figure 1.

These results evidenced that reported by [18-20], indicating that with higher PLA content there was higher modulus and tensile strength, given that adding PLA can increase the material's rigidity [12] functioning as a reinforcement for [21]. Upon being mixed, it is possible that the PLA characteristics increased the low mechanical properties of the pure TPS, perhaps because of a higher polar interaction between the starch and PLA carboxyl groups, attributable to the possible hydrogen bond produced between the carbonyl group

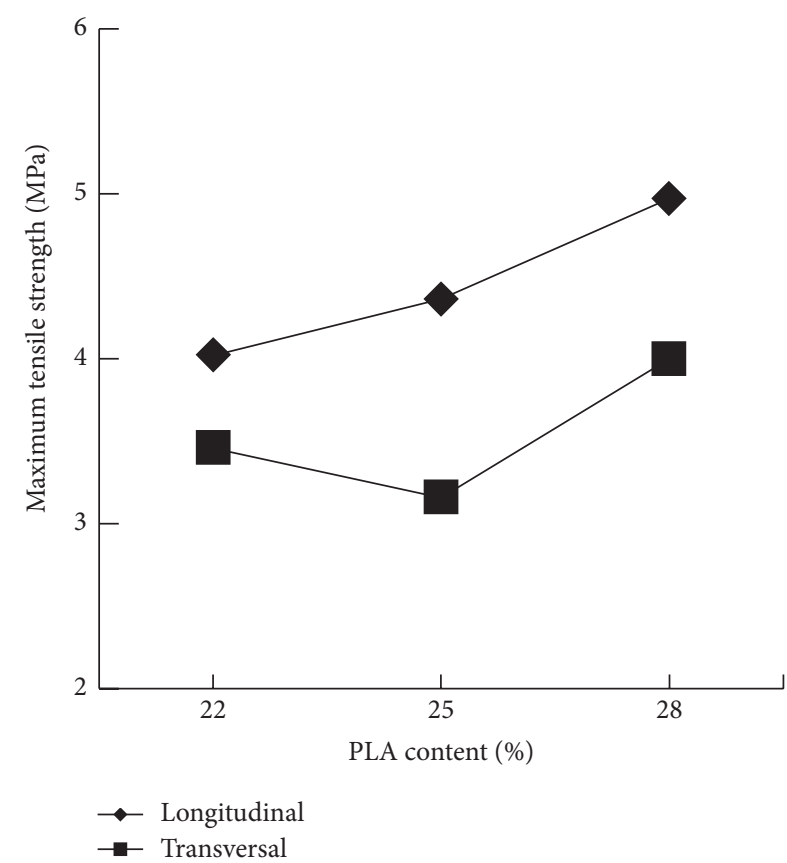

FIGURE 1: Behavior of maximum tensile strength against polylactic acid content.

(i.e., ester bond) of the PLA and the hydroxyl group in the starch [22].

In addition, with lower PLA values (22\%), mechanical properties decreased [23]; this was probably because the humidity present in the starch reduced the PLA molecular weight caused by hydrolysis [24], given that PLA degradation is generally attributed to hydrolysis of the ester bonds in the presence of a given level of water [25], which is why a higher TPS content generated higher humidity, causing a negative effect on mechanical properties, like elastic modulus and maximum tensile strength. For the grafted PLA, its molecules contain some anhydride residues capable of activating chain scissions of the PLA molecules, for the blend in melted state, through a hydrolysis mechanism diminishing the PLA molecular weight. This reduction of the PLA chain length in the blend may have contributed to the diminishing of the tensile properties of some blends [26].

Regarding elongation, $[27,28]$ reported that the main inconvenience in TPS/PLA blends is precisely their low elongation, with values even below $6 \%$ as soon as the TPS concentration in the blend exceeds 10\% (Figure 4). In light of this, [29] considered the possibility that PLA formed immiscible dispersions within TPS, leading to the little elongation of the final material. It has been found that elongation diminishes as starch concentration increases [30, 31], a situation contrasting with the case analyzed, where, with the higher starch content, the highest elongation indices were found, coinciding with that reported by [23]. For $22 \%$ PLA, elongation was on average $17.72 \%$; for treatments with higher PLA concentration, elongation was 9\%. Against this, the hygroscopic properties of starch and the plasticizer 
TABLE 1: Results of tensile mechanical properties.

\begin{tabular}{|c|c|c|c|c|c|c|c|}
\hline \multirow{2}{*}{\multicolumn{2}{|c|}{ Treatment* }} & \multicolumn{2}{|c|}{$\begin{array}{l}\text { Elastic modulus } \\
\qquad(\mathrm{MPa})\end{array}$} & \multicolumn{2}{|c|}{$\begin{array}{l}\text { Maximum tensile strength } \\
(\mathrm{MPa})\end{array}$} & \multicolumn{2}{|c|}{$\begin{array}{c}\text { Maximum elongation } \\
\text { at the rupture point } \\
(\%)\end{array}$} \\
\hline & & Long & Trans & Long & Trans & Long & Trans \\
\hline 1 & A1P1T1 & $104.71 \pm 0.20$ & $85.46 \pm 1.24$ & $3.19 \pm 0.19$ & $2.57 \pm 0.05$ & $14.02 \pm 3.47$ & $16.22 \pm 0.53$ \\
\hline 2 & A1P1T2 & $211.96 \pm 1.51$ & $146.41 \pm 0.49$ & $4.23 \pm 0.13$ & $3.68 \pm 0.25$ & $9.92 \pm 0.92$ & $13.88 \pm 3.81$ \\
\hline 3 & A1P1T3 & $161.63 \pm 0.06$ & $99.05 \pm 0.70$ & $3.45 \pm 0.12$ & $2.76 \pm 0.06$ & $10.41 \pm 0.49$ & $7.63 \pm 0.76$ \\
\hline 4 & A1P2T1 & $230.06 \pm 0.31$ & $139.13 \pm 0.42$ & $4.25 \pm 0.20$ & $3.53 \pm 0.04$ & $7.92 \pm 1.61$ & $10.47 \pm 0.42$ \\
\hline 5 & A1P2T2 & $231.32 \pm 2.00$ & $165.90 \pm 1.51$ & $4.06 \pm 0.04$ & $3.77 \pm 0.06$ & $6.01 \pm 0.54$ & $11.45 \pm 0.61$ \\
\hline 6 & A1P2T3 & $193.41 \pm 0.50$ & $98.17 \pm 0.92$ & $3.63 \pm 0.06$ & $2.15 \pm 0.07$ & $7.15 \pm 0.74$ & $6.81 \pm 0.96$ \\
\hline 7 & A1P3T1 & $259.05 \pm 0.71$ & $112.23 \pm 0.55$ & $4.76 \pm 0.28$ & $2.73 \pm 0.12$ & $13.09 \pm 2.74$ & $5.84 \pm 1.11$ \\
\hline 8 & A1P3T2 & $189.07 \pm 0.50$ & $205.65 \pm 0.68$ & $3.53 \pm 0.12$ & $4.47 \pm 0.28$ & $5.86 \pm 0.68$ & $10.95 \pm 0.19$ \\
\hline 9 & A1P3T3 & $291.02 \pm 1.2$ & $146.73 \pm 0.66$ & $4.99 \pm 0.37$ & $4.06 \pm 1.17$ & $9.36 \pm 1.96$ & $10.62 \pm 0.87$ \\
\hline 10 & A2P1T1 & $141.62 \pm 0.25$ & $119.60 \pm 0.24$ & $3.51 \pm 0.18$ & $3.77 \pm 0.09$ & $9.41 \pm 1.68$ & $17.59 \pm 1.09$ \\
\hline 11 & A2P1T2 & $209.13 \pm 1.58$ & $87.13 \pm 1.02$ & $4.32 \pm 0.12$ & $3.48 \pm 0.14$ & $11.43 \pm 0.46$ & $22.76 \pm 2.68$ \\
\hline 12 & A2P1T3 & $195.77 \pm 0.46$ & $149.32 \pm 0.64$ & $4.22 \pm 0.02$ & $3.73 \pm 0.07$ & $12.12 \pm 0.73$ & $12.17 \pm 2.71$ \\
\hline 13 & $\mathrm{~A} 2 \mathrm{P} 2 \mathrm{~T} 1$ & $151.56 \pm 0.79$ & $121.33 \pm 0.04$ & $4.03 \pm 0.18$ & $3.72 \pm 0.14$ & $16.92 \pm 1.81$ & $18.46 \pm 2.02$ \\
\hline 14 & $\mathrm{~A} 2 \mathrm{P} 2 \mathrm{~T} 2$ & $216.35 \pm 0.55$ & $174.56 \pm 0.36$ & $4.32 \pm 0.18$ & $4.39 \pm 0.05$ & $8.90 \pm 0.21$ & $18.60 \pm 2.12$ \\
\hline 15 & A2P2T3 & $257.91 \pm 0.56$ & $118.28 \pm 0.30$ & $4.60 \pm 0.13$ & $3.02 \pm 0.02$ & $12.15 \pm 1.05$ & $10.46 \pm 1.75$ \\
\hline 16 & A2P3T1 & $234.89 \pm 2.48$ & $271.52 \pm 0.85$ & $4.55 \pm 0.10$ & $5.55 \pm 0.31$ & $8.46 \pm 1.09$ & $8.57 \pm 0.77$ \\
\hline 17 & A2P3T2 & $323.69 \pm 0.85$ & $277.03 \pm 0.27$ & $5.69 \pm 0.32$ & $4.87 \pm 0.34$ & $8.84 \pm 1.14$ & $7.63 \pm 1.92$ \\
\hline 18 & A2P3T3 & $309.57 \pm 1.17$ & $228.26 \pm 3.86$ & $5.09 \pm 0.26$ & $4.48 \pm 0.12$ & $6.10 \pm 1.06$ & $11.04 \pm 2.36$ \\
\hline 19 & A3P1T1 & $188.97 \pm 1.35$ & $86.43 \pm 0.25$ & $4.30 \pm 0.09$ & $3.67 \pm 0.07$ & $24.38 \pm 1.46$ & $31.14 \pm 0.42$ \\
\hline 20 & A3P1T2 & $232.86 \pm 2.92$ & $142.60 \pm 0.22$ & $4.93 \pm 0.22$ & $4.32 \pm 0.21$ & $25.88 \pm 1.92$ & $23.35 \pm 0.99$ \\
\hline 21 & A3P1T3 & $146.33 \pm 2.68$ & $90.33 \pm 0.13$ & $4.01 \pm 0.09$ & $3.16 \pm 0.07$ & $18.92 \pm 1.53$ & $14.75 \pm 3.63$ \\
\hline 22 & A3P2T1 & $138.93 \pm 5.35$ & $72.90 \pm 0.36$ & $3.65 \pm 0.09$ & $1.70 \pm 0.18$ & $15.99 \pm 2.28$ & $9.26 \pm 1.10$ \\
\hline 23 & A3P2T2 & $278.58 \pm 2.99$ & $63.84 \pm 0.38$ & $5.11 \pm 0.33$ & $2.64 \pm 0.04$ & $19.48 \pm 2.19$ & $10.37 \pm 1.09$ \\
\hline 24 & А3Р2T3 & $332.50 \pm 1.34$ & $163.73 \pm 0.40$ & $5.62 \pm 0.09$ & $3.57 \pm 0.20$ & $13.84 \pm 1.66$ & $11.58 \pm 1.29$ \\
\hline 25 & A3P3T1 & $227.07 \pm 0.35$ & $95.02 \pm 0.68$ & $4.38 \pm 0.13$ & $2.98 \pm 0.29$ & $10.46 \pm 2.52$ & $9.98 \pm 1.07$ \\
\hline 26 & A3Р3T2 & $406.32 \pm 1.21$ & $200.44 \pm 0.30$ & $6.77 \pm 0.11$ & $3.59 \pm 0.05$ & $20.72 \pm 1.40$ & $5.82 \pm 0.55$ \\
\hline 27 & A3P3T3 & $274.65 \pm 1.18$ & $109.74 \pm 0.59$ & $4.94 \pm 0.28$ & $3.32 \pm 0.44$ & $25.18 \pm 0.20$ & $10.58 \pm 2.33$ \\
\hline
\end{tabular}

${ }^{*}$ Coupling agent: $\mathrm{A} 1=0.5 \% ; \mathrm{A} 2=0.87 \% ; \mathrm{A} 3=1.23 \%$. Polylactic acid: $\mathrm{P} 1=22 \% ; \mathrm{P} 2=25 \% ; \mathrm{P} 3=28 \%$. Temperature profile: $\mathrm{T} 1=153.30^{\circ} \mathrm{C} ; \mathrm{T} 2=155.75^{\circ} \mathrm{C} ; \mathrm{T} 3=$ $158.00^{\circ} \mathrm{C}$.

could have interrupted the polymer-polymer and polymerplasticizer interactions by substituting the polymer-water and water-plasticizer interactions, leading to reduced rigidity of the polymer, allowing the water absorbed by TPS to facilitate mobility of starch chains, thus resulting in increased elongation [20].

In most cases, it was seen how higher PLA content provided higher elastic modulus values in longitudinal and transversal direction. A similar situation occurred with maximum tensile strength, but contrary to what happened with maximum elongation in the transversal direction where the higher PLA content generated minor results of this response variable.

Also, the coupling agent content was the most influential factor on maximum elongation in longitudinal direction. It was found that with the maximum coupling agent content the highest maximum elongation values were obtained, increasing this property by approximately $163 \%$, compared to treatments presenting lower elongation values, showing in $71.4 \%$ of the cases a directly proportional relationship between increased coupling agent content and maximum elongation values.

Miscibility and interface adhesion play an essential role in the mechanical properties of the polymer blends, where, generally, higher mechanical properties are expected when high interface adhesion and miscibility of the components exist [28]. Additionally, it may be expected that with higher AA content the percentage of graft in the PLA would be higher, increasing the possibilities of forming macroradicals that can react [18] and, because the effectiveness of the graft will depend on the monomer concentration [32], it is then feasible that under this coupling agent content there would 


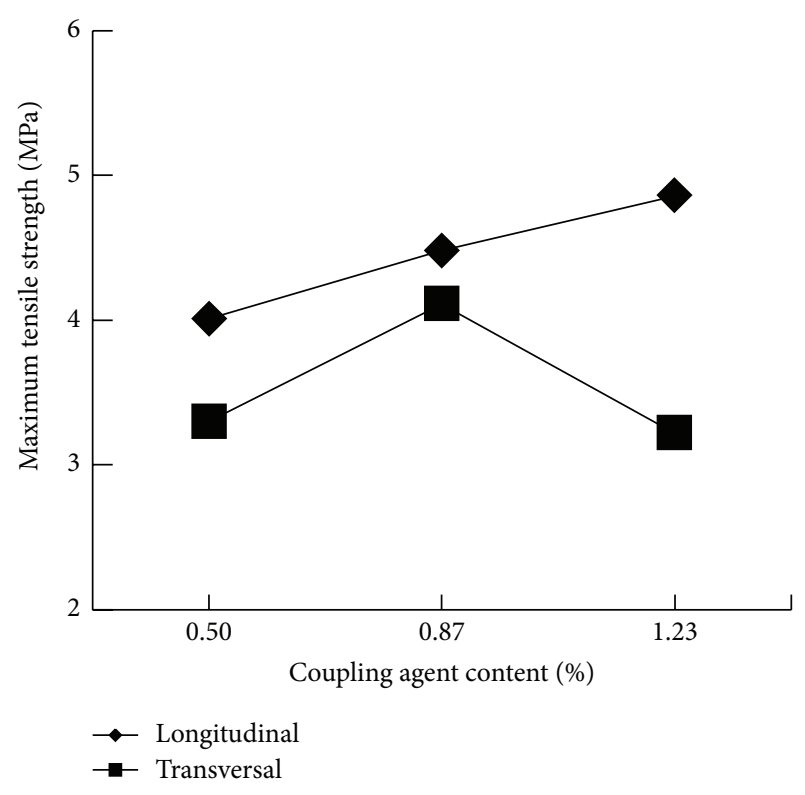

FIGURE 2: Behavior of maximum tensile strength against the coupling agent content.

be outstanding indices of miscibility among the phases, positively affecting the mechanical properties of the final material.

However, excessive coupling agent may act as plasticizer and be responsible for the decrease in the maximum tensile strength [11], thus explaining how the maximum tensile strength values coincided with the intermediate level of coupling agent content, noted in Figure 2, due possibly to a separation of phases induced by secondary reactions (chain degradation, homopolymerization of maleic anhydride, discoloration, and reticulation) or terminal reactions [20], produced after a concentration beyond the optimal one. Secondary reactions are common in the reaction of free radicals, like, for example, $\beta$-scission. The probability of these occurring depends largely on the nature of the macroradicals and the polymer chain. For grafted PLA systems, two possible secondary reactions may have occurred: scission of the chain caused by thermohydrolysis and ramification of the PLA substrate. Excessive scission may have led to lower molecular weight and decreased properties of the polymer, while the ramification may have been disadvantageous to monomer attachment, given that most of its free radicals could attach to the lateral chains produced by this secondary reaction, thus limiting the action of the graft [18].

Also, it is feasible that, in the combinations where the minimum level of the coupling agent $(0.5 \%)$ was managed, there would be inconveniences in compatibility due to an insufficient amount of the monomer, incapable of efficiently binding the TPS and PLA phases, an issue that evidenced the difficulty for film production with this coupling level where blowing problems emerged, presenting materials with great amounts of agglomerations, often with greater thickness, and maintaining a rather low torque, making the bubble output occur too slowly.

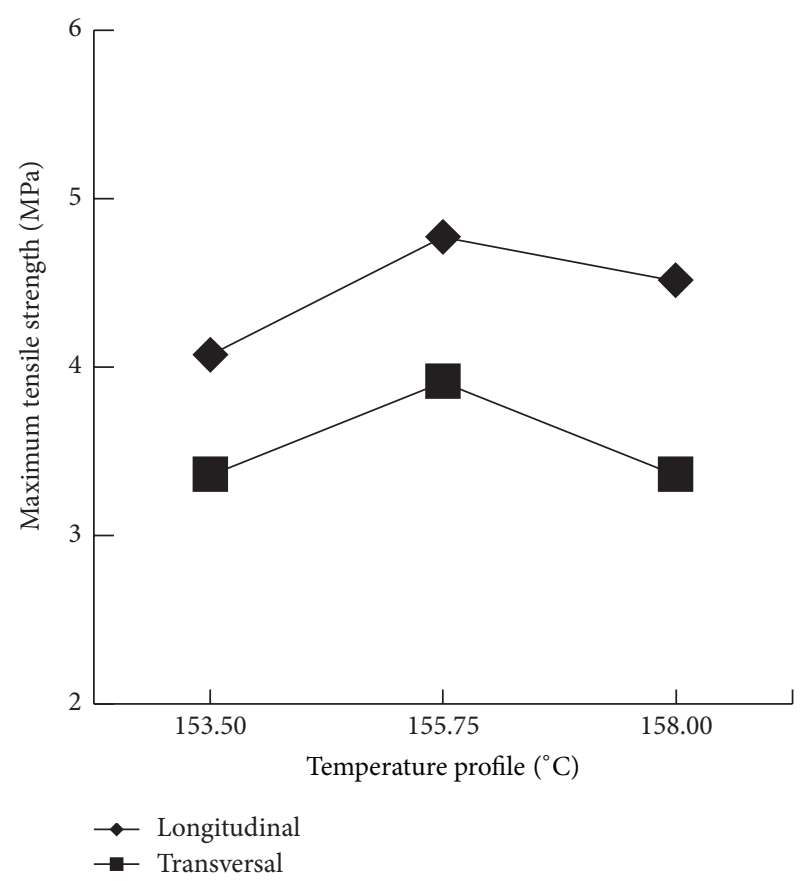

FIGURE 3: Behavior of maximum tensile strength against the temperature profile.

The temperature profile was the factor that generated the least effect on the maximum tensile strength. With respect to elongation, no significant differences were evident between its levels. Although its effect was not the highest, compared to the PLA content and AA, some tendencies can be highlighted. For the elastic modulus and maximum tensile strength, the highest values were found for these response variables in the intermediate temperature profile, while for elongation a clear tendency was not evidenced, given that the higher indices were shared between the first two profiles. Perhaps the action of $155.75^{\circ} \mathrm{C}$ may have permitted higher compatibilization of the blends, favoring polymerization of graft of free radicals, where the indicator agent could decompose rapidly and completely, producing higher amounts of macroradicals that, in turn, gave way to a higher degree of graft, as reported by [18], evidenced in the behavior shown in Figure 3.

Excessive temperatures could cause degradation of both reaction initiators [33] as maleic anhydride, causing the breaking of the coupling between phases [34], in films processed with the maximum temperature, possibly reducing the molecular weight of PLA [20]. Likewise, TPS molecular weight could lose excessive action of temperature limiting function to reinforce this PLA [21] negatively influencing the material's final properties. From the aforementioned, it has been postulated that the PLA's thermal degradation is produced principally through random scissions of the principal chain, and several of these include hydrolysis, depolymerization, oxidative degradation, and intramolecular transesterification reactions, which could have participated in the degradation process for the thermal treatments [35], associated mainly with hydrolysis of the ester groups and accelerated by $-\mathrm{COOH}$ terminal groups [25]. 


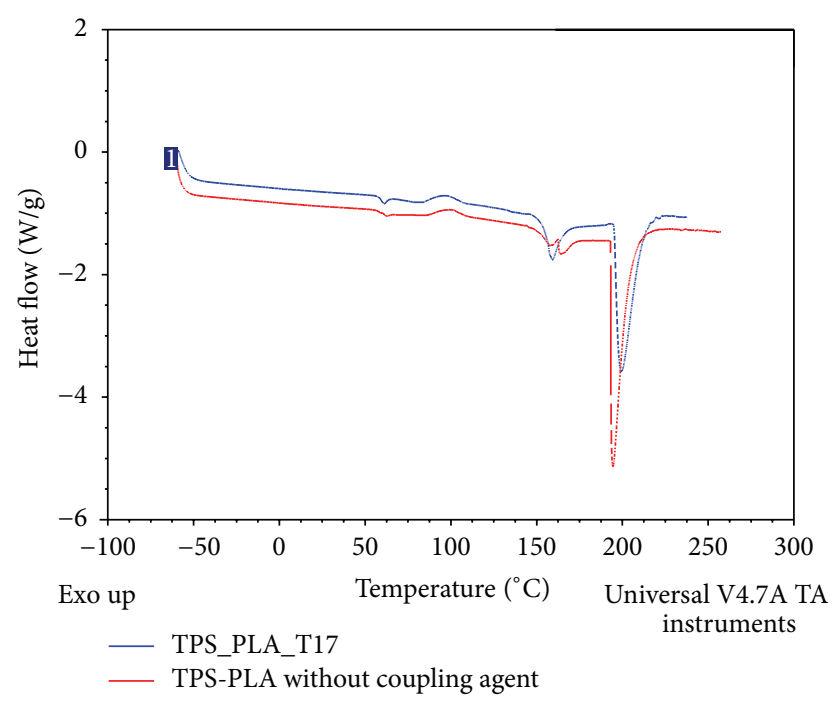

FIGURE 4: DSC of samples of TPS/PLA blends.

The interaction of the PLA-AA-temperature profile factors presented a significant effect upon the three response variables. In light of this, it is well known that the mechanical behavior of heterogeneous materials like TPS/PLA depends on some principal parameters, which include the modulus of each component, the volume fraction of each element, the ratio of the morphology aspect, the filler material, distribution of the length, orientation of the chains, and properties of the interface, given their responsibility in charge transfer. The last parameter depends mainly upon the degree of the interactions among the phases [36]. Due to the aforementioned, it could be deducted how the triple interaction of the factors could have been generated on the response variables, bearing in mind that the PLA content was employed, which has to do with the first and second parameters previously mentioned, the concentration of AA, directly implied in the interface properties, and the temperature profile, related to the morphology and blend coupling.

Of the three response variables observed, the elastic modulus was the variable upon which the highest effect was generated by the three factors, in both longitudinal and transversal directions. With respect to this, it was found that the minimum value obtained was $104.71 \pm 0.20 \mathrm{MPa}$, corresponding to treatment 1 (A1P1T1), while the maximum was $406.32 \pm 1.21 \mathrm{MPa}$ in treatment 26 (A3P3T2), in longitudinal direction. Additionally, in transversal direction in treatment 23 (A3P2T2), the lowest value was found with $63.84 \pm 0.38 \mathrm{MPa}$, while, with a value of $277.03 \pm 0.27 \mathrm{MPa}$, treatment 17 (A2P3T2) offered the highest indices in this variable. From this, it may be seen how with the highest PLA content (28\%) and with the second temperature profile $\left(155.75^{\circ} \mathrm{C}\right)$ the highest indices of elastic modulus were found, in both directions. This, somehow, evidences the behavior reflected upon analyzing both factors separately.

Regarding the maximum tensile strength, it was found that the values are within a range from $3.19 \pm 0.19 \mathrm{MPa}$ from treatment 1 (A1P1T1) to $6.77 \pm 0.11 \mathrm{MPa}$, corresponding to treatment 26 (A3P3T2) in longitudinal direction.
For the transversal direction, treatment 22 (A3P2T2) yielded the lowest value with $1.70 \pm 0.18 \mathrm{MPa}$ and treatment 17 (A2P3T2) yielded the highest index with $4.87 \pm 0.34 \mathrm{MPa}$. This permits observing that, as with the elastic modulus, higher indicators of maximum tensile strength were obtained with the highest PLA content and the second temperature profile. The values obtained are higher than those found by some studies on TPS/PLA blends. For elongation, treatment 8 (A1P3T2) yielded the lowest value with $5.86 \pm 0.68 \%$, while treatment 20 (A3P1T2) presented the highest indices with $25.88 \pm 1.92 \%$, in longitudinal direction. Additionally, in transversal direction, the treatment with the lowest value was 26 (A3P3T2) with $5.82 \pm 0.55 \%$ and treatment 19 (A3P1T1) with $31.14 \pm 0.42 \%$ offered the highest values.

According to [37], for a composite material that includes a coupling agent or grafted compatibilizer, wetting and the bond to the interface significantly influence the properties of composite materials.

The formation of interfacial molecular contact through wetting is the prerequisite for adhesive bond [24]. Due to this, the molecules diffuse and react chemically to establish covalent bonds through the interface while molecular diffusion is generally accelerated by reduced surface tension [36], which can be achieved by adding compatibilizer and subsequent establishment of chemically stable covalent bonds [18], where, possibly, in treatments with outstanding mechanical properties, high degrees of wetting and consequential bond of their interface were reached. This is perhaps because the blend conditions permitted adjusted homopolymerization of maleic anhydride, without being excessive, through a secondary reaction, producing low-molecular weight polymers that acted as plasticizers and diminished the interface energy between both phases, facilitating the wetting of the starch with the PLA [38], causing its final properties to be increased against other treatments in which these phenomena could have been reduced by diverse factors, like the insufficient amount of AA or the excessive action of temperature.

Between the two treatments shown, some considerations were kept in mind: treatment 26 (A3P3T2) offered higher values in the three response variables in longitudinal direction, but the situation was inverted in transversal direction, where treatment 17 (A2P3T2) showed the highest indices. If bidirectionality is considered, it can be seen that, for maximum tensile strength, treatment 26 presented an unbalance of $103 \%$ in the transversal direction with respect to the longitudinal direction, while for treatment 17 this disproportion was reduced to $16.8 \%$. The same occurred with the other response variables, where treatment 17 presented the highest bidirectionality, a favorable issue for a material, given its functionality and quality, which permitted more uniform chain distribution and not as unbalanced as in treatment 26. Another advantage of treatment 17 against treatment 26 was the cost of the materials. As observed, the only difference between the combinations lies in the coupling agent content; the first presents a content of $0.87 \%$, while the second is of $1.23 \%$. This $0.36 \%$ difference is significant in terms of costs, given that at industrial scale it can represent considerable amounts of money, bearing in mind the high cost of commercial AA. 
TABLE 2: Comparison results of tensile mechanical properties.

\begin{tabular}{|c|c|c|c|c|c|c|c|}
\hline \multirow{2}{*}{\multicolumn{2}{|c|}{ Treatment* }} & \multicolumn{2}{|c|}{$\begin{array}{l}\text { Elastic modulus } \\
\qquad(\mathrm{MPa})\end{array}$} & \multicolumn{2}{|c|}{$\begin{array}{l}\text { Maximum tensile strength } \\
(\mathrm{MPa})\end{array}$} & \multicolumn{2}{|c|}{$\begin{array}{c}\text { Maximum elongation } \\
\text { at the rupture point } \\
(\%)\end{array}$} \\
\hline & & Long & Trans & Long & Trans & Long & Trans \\
\hline 1 & $\mathrm{~T} 17$ & $323.69 \pm 0.85$ & $277.03 \pm 0.27$ & $5.69 \pm 0.32$ & $4.87 \pm 0.34$ & $8.84 \pm 1.14$ & $7.63 \pm 1.92$ \\
\hline 2 & TPS/PLA* ${ }^{*}$ & $266.23 \pm 0.39$ & $173.49 \pm 0.58$ & $4.13 \pm 0.10$ & $3.40 \pm 0.19$ & $17.11 \pm 2.65$ & $16.54 \pm 2.23$ \\
\hline
\end{tabular}

${ }^{*}$ Without coupling agent.

Maleic anhydride concentration of $0.87 \%$ is lower than other reports such as [39], which used higher levels, resulting in low mechanical properties possibly caused by a greater degree of hydrolysis of starch polymer chains. According to the above, [40], who used a concentration of $2 \%$, suggested using smaller amounts of maleic anhydride in order to improve the adhesion and compatibility of TPS and PLA. Considering the above suggestion, [38] employed a concentration of $1 \%$ of maleic anhydride to generate adhesion TPS with PLA because, at higher concentrations, possibly hydrolysis is generated, which could cause a decrease in properties.

For comparison, a film with PLA and TPS blend without inclusion of coupling agent was obtained using the same methodology. The mechanical properties of the material obtained are shown in Table 2. Treatment 17 was compared with another mixture of TPS and PLA without coupling agent, by Student $t$-test $(P<0.05)$, finding in their mechanical properties significant differences in elastic modulus, high tensile strength, and elongation, in longitudinal and transverse directions. Treatment 17 had higher strength values 38.0 and $42.9 \%$ lengthwise and crosswise, respectively, as compared to the film without coupling agent, demonstrating that greater interaction between material phases can cause increases in strength properties. The film without coupling agent provided a surface from which the phase separation of the PLA and TPS, with some cracks and irregularities, also evidenced its thickness which was $37.5 \%$ higher than the film thickness of treatment 17.

3.2. Differential Scanning Calorimetry (DSC). The results in Table 3 correspond to data obtained from thermograms; herein, temperatures and melting enthalpies $\left(T_{m}\right.$ and $\left.\Delta H_{m}\right)$ are indicated along with a temperature signal and crystallization enthalpy ( $T_{c}$ and $\Delta H_{c}$ ), as well as a glass transition temperature $\left(T_{g}\right)$. During the test, two heating moments were carried out; the first, denominated run 1, obtained data corresponding to TPS, given that the second no longer showed the transitions for this component, which explains an amorphous state of the TPS after subjecting it to high temperatures with its subsequent cooling [2], while the second, called run 2, presented PLA values according to the blend analyzed.

For the film made up of the TPS/PLA binary blend (T17), some behaviors took place, for example, in run 1 , although other melting peaks were present, the last of these was assigned to the TPS, found between 190 and $210^{\circ} \mathrm{C}$,
TABle 3: Phase transitions of the flexible films.

\begin{tabular}{lcccccc}
\hline \multirow{2}{*}{ Blend } & Components & $\begin{array}{c}T_{g} \\
\left({ }^{\circ} \mathrm{C}\right)\end{array}$ & $\begin{array}{c}T_{c} \\
\left({ }^{\circ} \mathrm{C}\right)\end{array}$ & $\begin{array}{c}\Delta H_{c} \\
(\mathrm{~J} / \mathrm{g})\end{array}$ & $\begin{array}{c}T_{m} \\
\left({ }^{\circ} \mathrm{C}\right)\end{array}$ & $\begin{array}{c}\Delta H_{m} \\
(\mathrm{~J} / \mathrm{g})\end{array}$ \\
\hline \multirow{2}{*}{$\mathrm{T} 17$} & TPS & - & - & - & 199.35 & 72.55 \\
& PLA & 59.04 & 97.48 & 5.48 & 159.17 & 17.23 \\
\hline \multirow{2}{*}{ TPS/PLA $^{*}$} & TPS & - & - & - & 194.50 & 80.96 \\
& PLA & 60.90 & 100.74 & 4.11 & 163.88 & 11.59 \\
\hline
\end{tabular}

${ }^{*}$ Without coupling agent.

approximately, determining only its temperature and melting enthalpy. Additionally, for the second run, it was possible to establish that the glass transition temperature of PLA was $59.04^{\circ} \mathrm{C}$, followed by crystallization signals, between 90 and $110^{\circ} \mathrm{C}$, approximately. Finally, the melting temperature for PLA was found at $159.17^{\circ} \mathrm{C}$, corresponding to the last peak presented in run 2.

Some dispositions were evidenced in the pattern film of TPS/PLA without coupling agent. As with the previous case, the first run analyzed the TPS behavior; from here, its melting temperature was obtained at $194.50^{\circ} \mathrm{C}$. For the second run, crystallization signal and, lastly, the PLA melting peak of PLA were determined. From this, it was observed how the PLA melting enthalpy for the pattern film was quite inferior to that presented by the PLA in the TPS/PLA blend, which could be an indicator of the percentage of crystallinity of the composite materials. Thereby, diminished $\Delta H_{m}$ could be indicative of diminished crystallinity [18]. This crystallinity increase produced in the TPS/PLA film may have been caused by the nucleation of starch and the degradation of PLA polymer chains, given that starch was able to act as nucleation agent for crystallization and the molecular weight affected polymer crystallization [24]. Further, the plasticizer-like glycerol could have also migrated to the PLA matrix, causing increased mobility of the polymer chain, thus, increasing the PLA crystallization rate [31]. Diminished $\Delta H_{m}$ and hence crystallinity in starch and PLA blends could have been because the starch limits the movement of the polymer segments, hindering reorganization of the polymer chain [18]. Regarding crystallization enthalpy, $\Delta H_{c}$ was presented by the polylactic acid in both films, where the one containing TPS/PLA without coupling agent presented 33.3\% reduction against the TPS/PLA blend film. Although starch may function as nucleation agent, it is also possible that it interferes with the mobility of the PLA chain, slightly reducing the PLA crystallinity [24] of the pattern film. When comparing 
crystallinity according to [32], taking as a reference that $\Delta H_{m}$ of the $100 \%$ crystalline PLA is of $93 \mathrm{~J} / \mathrm{g}$ [33], the PLA of the TPS/PLA film would present a crystallinity of $18.5 \%$, quite above the $12.5 \%$ shown with the PLA of the pattern film. This would indicate that in the film of the treatment chosen a higher degree of crystallization may have been generated.

Authors like [33] have reported that pure PLA 4032 presents $T_{g}$ of $61.3^{\circ} \mathrm{C}$. For the case presented, $T_{g}$ of the PLA in the TPS/PLA blend was of $59.04^{\circ} \mathrm{C}$. This may be because the mobility of the PLA chain was increased due to the plasticization effect brought by the glycerol gelatinized starch [6], as well as the formation of cyclic oligomers through "backbiting" reactions [34]. However, authors like [24, 31] state that the glass transition temperature $\left(T_{g}\right)$ of PLA is not affected by the incorporation of TPS; thereby, more in-depth studies would be needed to test the certainty or falsehood of this hypothesis. It is known that the plasticizer can diminish the polymer's glass transition temperature. Although the coupling agent was introduced as a reactive compatibilizer, it could also have acted as a plasticizer [24] reducing the PLA's glass transition temperature in the TPS/PLA blend. The melting enthalpy $\left(\Delta H_{m}\right)$ for the pure PLA $(36.5 \mathrm{~J} / \mathrm{g})$ is higher than that presented by the PLA of the TPS/PLA blend $(17.23 \mathrm{~J} / \mathrm{g})$. This reduction was possibly because the ramifications generated in the grafted PLA disturbed the regularity of the PLA chain structures, thus, increasing the space among them [18].

Although, according to the results of differential scanning calorimetry, films TPS/PLA with and without coupling agent showed a similar behavior in terms of values of thermal transitions, there were differences in mechanical and surface properties between the two films. In the film TPS/PLA (T17), higher values of tensile strength, a more homogeneous surface, and fineness, without irregularities and with a significantly reduced thickness, were found.

The maleic anhydride can promote transesterification/ esterification reactions between the starch and MA molecules improving its compatibility with other biopolymers as manifested [39]. In the investigation by [41], they found that the inclusion of maleic anhydride to PLA further mixed with starch improves the mechanical properties of the flexible film obtained, achieving compatible polar groups starch, with the nonpolar component of PLA. Meanwhile, [42] used the maleic anhydride because it reduces the interfacial tension between phases improving adhesion of starch and PLA, resulting in thinner films and a more uniform and stable morphology, showing improved mechanical properties.

Due to the aforementioned reasons, it was determined that treatment 17 (A2P3T2) represented the formulation that offered outstanding mechanical properties, higher bidirectional balance, and the possibility of greater cost reduction of raw materials to obtain the flexible film.

\section{Conclusions}

The factors evaluated, polylactic acid content, coupling agent, and temperature profile, as well as their interaction, generated significant effects on the response variables in both longitudinal and transversal directions. From this, the formulation that included $28 \%$ PLA content, $0.87 \%$ coupling agent processed at extrusion temperature of $155.75^{\circ} \mathrm{C}$ presented outstanding mechanical properties against the remaining combinations included in the design. With the formulation found, we managed to reduce by $55.6 \%$ the coupling agent content in the material, compared to prior research conducted by the CYTBIA research group, probably influencing the diminished costs of the final material; although against starch-based materials, we managed to obtain a film with outstanding mechanical properties, but still with deficiencies against synthetic materials.

\section{Conflict of Interests}

The authors declare that they have no conflict of interests regarding the publication of this paper.

\section{References}

[1] L. Reddy, S. Reddy, and A. Gupta, "Study of bio-plastics as green and sustainable alternative to plastics," International Journal of Emerging Technology and Advanced Engineering, vol. 3, no. 5, pp. 76-81, 2013.

[2] M. M. Reddy, S. Vivekanandhan, M. Misra, S. K. Bhatia, and A. K. Mohanty, "Biobased plastics and bionanocomposites: current status and future opportunities," Progress in Polymer Science, vol. 38, no. 10-11, pp. 1653-1689, 2013.

[3] M. Valero, M. Ortegón, and Y. Uscategui, "Biopolímeros: avances y perspectivas," Dyna, vol. 80, no. 181, pp. 171-180, 2013.

[4] J. J. G. Van Soest and J. F. G. Vliegenthart, "Crystallinity in starch plastics: consequences for material properties," Trends in Biotechnology, vol. 15, no. 6, pp. 208-213, 1997.

[5] L. Jiang and J. Zhang, "Biodegradable polymers and polymer blends," in Handbook of Biopolymers and Biodegradable Plastics: Properties, Processing and Applications, S. Ebnesajjad, Ed., pp. 109-128, 2012.

[6] J. Cai, Z. Xiong, M. Zhou et al., “Thermal properties and crystallization behavior of thermoplastic starch/poly( $\varepsilon$-caprolactone) composites," Carbohydrate Polymers, vol. 102, pp. 746-754, 2014.

[7] F. C. Soares, F. Yamashita, C. M. O. Müller, and A. T. N. Pires, "Effect of cooling and coating on thermoplastic starch/ poly(lactic acid) blend sheets," Polymer Testing, vol. 33, pp. 3439, 2014.

[8] P. Sarazin, G. Li, W. J. Orts, and B. D. Favis, "Binary and ternary blends of polylactide, polycaprolactone and thermoplastic starch," Polymer, vol. 49, no. 2, pp. 599-609, 2008.

[9] J. Zhou, Y. Ma, L. Ren, J. Tong, Z. Liu, and L. Xie, "Preparation and characterization of surface crosslinked TPS/PVA blend films," Carbohydrate Polymers, vol. 76, no. 4, pp. 632-638, 2009.

[10] IHSQUÍMICA, "Biodegradable polymer," 2012, http://www.ihs .com/products/chemical/planning/ceh/biodegradable-polymers.aspx.

[11] M. Yao, "Modification of poly(lactic acid)/poly(propylene carbonate) blends through melt compounding with maleic anhydride," Express Polymer Letters, vol. 5, no. 11, pp. 937-949, 2011.

[12] M. A. Shirai, M. V. E. Grossmann, S. Mali, F. Yamashita, P. S. García, and C. M. O. Müller, "Development of biodegradable flexible films of starch and poly(lactic acid) plasticized with 
adipate or citrate esters," Carbohydrate Polymers, vol. 92, no. 1, pp. 19-22, 2013.

[13] N. Wang, J. Yu, P. R. Chang, and X. Ma, "Influence of citric acid on the properties of glycerol-plasticized dry starch (DTPS) and DTPS/poly(lactic acid) blends," Starch, vol. 59, no. 9, pp. 409417, 2007.

[14] N. Wang, J. Yu, P. R. Chang, and X. Ma, "Influence of formamide and water on the properties of thermoplastic starch/poly(lactic acid) blends," Carbohydrate Polymers, vol. 71, no. 1, pp. 109-118, 2008.

[15] M. Enriquez, R. Velasco, and V. Ortiz, "Composición y procesamiento de películas biodegradables basadas en almidón," Biotecnología en el Sector Agropecuario y Agroindustrial, vol. 10, no. 1, pp. 182-192, 2012.

[16] G. Moad, "Chemical modification of starch by reactive extrusion," Progress in Polymer Science, vol. 36, no. 2, pp. 218-237, 2011.

[17] ASTM International, ASTM D882-10. Standard Test Method for Tensile Properties of Thin Plastic Sheeting, ASTM International, West Conshohocken, Pa, USA, 2010.

[18] R. Zhu, Preparation of maleic anhydride grafted poly(lactid acid) (PLA) and its compatibilization effects on PLA/Soy protein composites, Tesis de Master en Ciencia de Materiales [M.S. thesis], Departamento de Ingeniería Mecánica y Materiales, Washington State University, Washington, DC, USA, 2011.

[19] R. Mendoza and J. Medina, "Propiedades adhesivas de mezclas de almidón de yuca termoplastificado y ácido poliláctico (TPS/PLA)," Revista INGE CUC, vol. 7, no. 1, pp. 217-228, 2011.

[20] S. Detyothin, Production and characterization of thermoplastic cassava starch, functionalized poly(lactic acid), and their reactive compatibilized blends [Tesis Doctor en Filosofía], Michigan State University, East Lansing, Mich, USA, 2012.

[21] T. Ke and X. Sun, "Effects of moisture content and heat treatment on the physical properties of starch and poly (lactic acid) blends," Journal of Applied Polymer Science, vol. 81, no. 12, pp. 3069-3082, 2001.

[22] T. Wittaya, "Rice starch-based biodegradable films: properties enhancement," in Structure and Function of Food Engineering, A. Amer, Ed., chapter 5, pp. 103-134, InTech, Rijeka, Croatia, 2012.

[23] N. Chapleau, M. A. Huneault, and H. Li, "Biaxial orientation of polylactide/thermoplastic starch blends," International Polymer Processing, vol. 22, no. 5, pp. 402-409, 2007.

[24] W. Y. Jang, B. Y. Shin, T. J. Lee, and R. Narayan, "Thermal properties and morphology of biodegradable PLA/starch compatibilized blends," Journal of Industrial and Engineering Chemistry, vol. 13, no. 3, pp. 457-464, 2007.

[25] P. Ma, P. Xu, M. Chen et al., "Structure-property relationships of reactively compatibilized $\mathrm{PHB} / \mathrm{EVA} /$ starch blends," Carbohydrate Polymers, vol. 108, no. 1, pp. 299-306, 2014.

[26] J. Wootthikanokkhan, P. Kasemwananimit, N. Sombatsompop, A. Kositchaiyong, S. Isarankura na Ayutthaya, and N. Kaabbuathong, "Preparation of modified starch-grafted poly(lactic acid) and a study on compatibilizing efficacy of the copolymers in poly(lactic acid)/thermoplastic starch blends," Journal of Applied Polymer Science, vol. 126, supplement 1, pp. E389-E396, 2012.

[27] M. A. Huneault and H. Li, "Morphology and properties of compatibilized polylactide/thermoplastic starch blends," Polymer, vol. 48, no. 1, pp. 270-280, 2007.
[28] S. Falah, Processing and properties of biodegradable polymer blends based on gelatinized potato starch [M.S. thesis], McMaster University, Hamilton, Canada, 2010.

[29] O. Martin and L. Avérous, "Poly(lactic acid): plasticization and properties of biodegradable multiphase systems," Polymer, vol. 42, no. 14, pp. 6209-6219, 2001.

[30] K. M. Nampoothiri, N. R. Nair, and R. P. John, "An overview of the recent developments in polylactide (PLA) research," Bioresource Technology, vol. 101, no. 22, pp. 8493-8501, 2010.

[31] C. M. O. Müller, A. T. N. Pires, and F. Yamashita, "Characterization of thermoplastic starch/poly(lactic acid) blends obtained by extrusion and thermopressing," Journal of the Brazilian Chemical Society, vol. 23, no. 3, pp. 426-434, 2012.

[32] A. Bhattacharya and B. N. Misra, "Grafting, a versatile means to modify polymers: techniques, factors and applications," Progress in Polymer Science, vol. 29, no. 8, pp. 767-814, 2004.

[33] J. Karl, Reactive Polymers Fundamentals and Applications. A Concise Guide to Industrial Polymers, William Andrew Publishing, Norwich, NY, USA, 2005.

[34] J. Castañeda, Estudio de la retrogradación en películas flexibles obtenidas a partir de mezclas de almidón nativo de yuca, ácido poli-láctico (PLA) y policaprolactona (PCL) [M.S. thesis], Escuela de Ingeniería de Materiales, Universidad del Valle, Cali, Colombia, 2012.

[35] M. Jamshidian, E. A. Tehrany, M. Imran, M. Jacquot, and S. Desobry, "Poly-Lactic Acid: production, applications, nanocomposites, and release studies," Comprehensive Reviews in Food Science and Food Safety, vol. 9, no. 5, pp. 552-571, 2010.

[36] A. Wang, R. Qi, C. Xiong, and M. Huang, "Effects of coupling agent and interfacial modifiers on mechanical properties of poly(lactic acid) and wood flour biocomposites," Iranian Polymer Journal, vol. 20, no. 4, pp. 281-294, 2011.

[37] S. Wu, Polymer Interface and Adhesion, Marcel Dekker, New York, NY, USA, 1982.

[38] V. H. Orozco, W. Brostow, W. Chonkaew, and B. L. López, "Preparation and characterization of poly (lactic acid)g-maleic anhydride and starch blends," Macromolecular Symposia, vol. 277, no. 1, pp. 69-80, 2009.

[39] J. B. Olivato, M. V. E. Grossmann, F. Yamashita, D. Eiras, and L. A. Pessan, "Citric acid and maleic anhydride as compatibilizers in starch/poly(butylene adipate-co-terephthalate) blends by one-step reactive extrusion," Carbohydrate Polymers, vol. 87, no. 4, pp. 2614-2618, 2012.

[40] D. Carlson, L. Nie, R. Narayan, and P. Dubois, "Maleation of polylactide (PLA) by reactive extrusion," Journal of Applied Polymer Science, vol. 72, no. 4, pp. 477-485, 1999.

[41] T. Yu, N. Jiang, and Y. Li, "Study on short ramie fiber/poly(lactic acid) composites compatibilized by maleic anhydride," Composites Part A: Applied Science and Manufacturing, vol. 64, pp. 139146, 2014.

[42] S. Detyothin, S. Selke, R. Narayan, M. Rubino, and R. Auras, "Effects of molecular weight and grafted maleic anhydride of functionalized polylactic acid used in reactive compatibilized binary and ternary blends of polylactic acid and thermoplastic cassava starch," Journal of Applied Polymer Science, vol. 132, no. 28, 15 pages, 2015. 

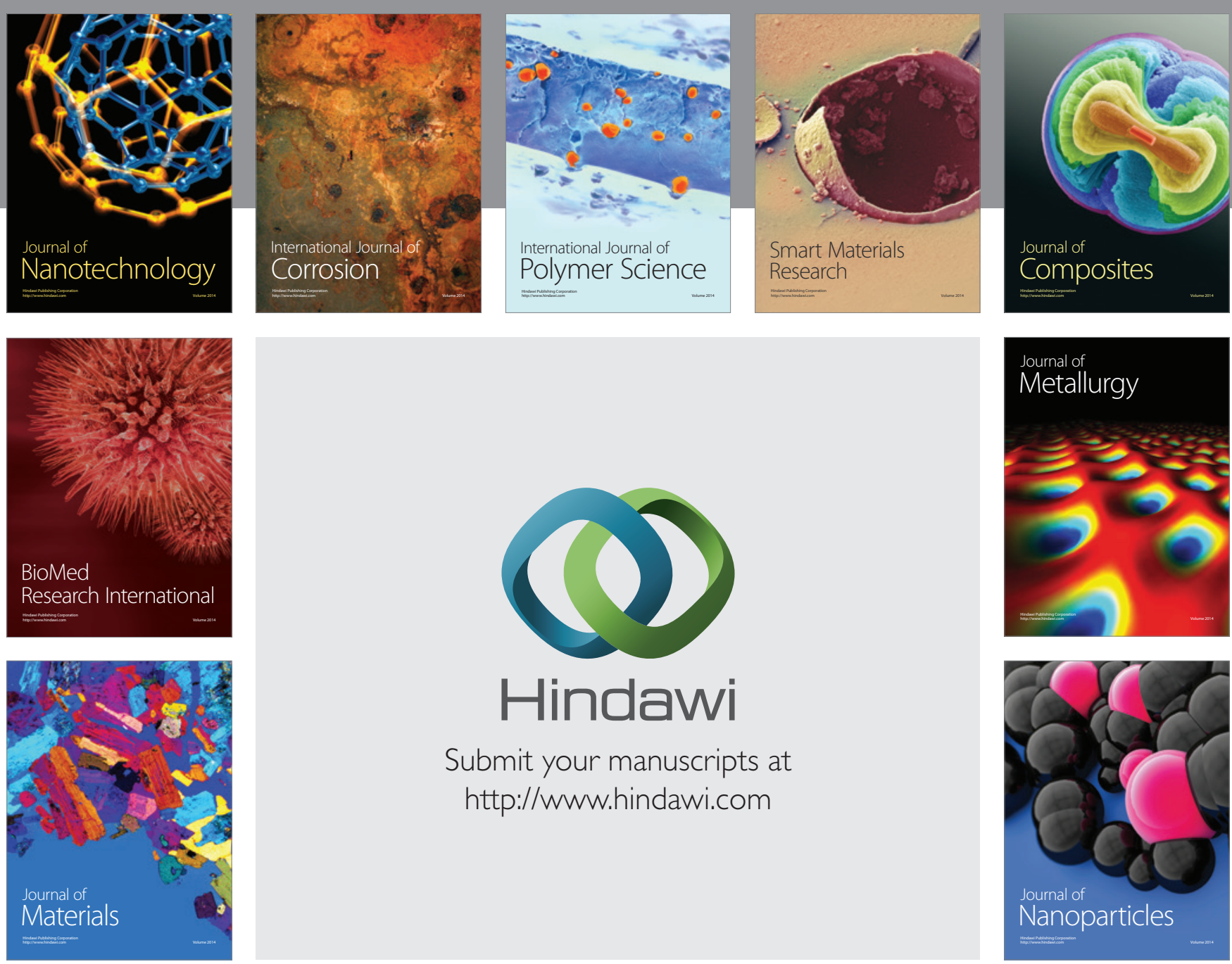

Submit your manuscripts at http://www.hindawi.com
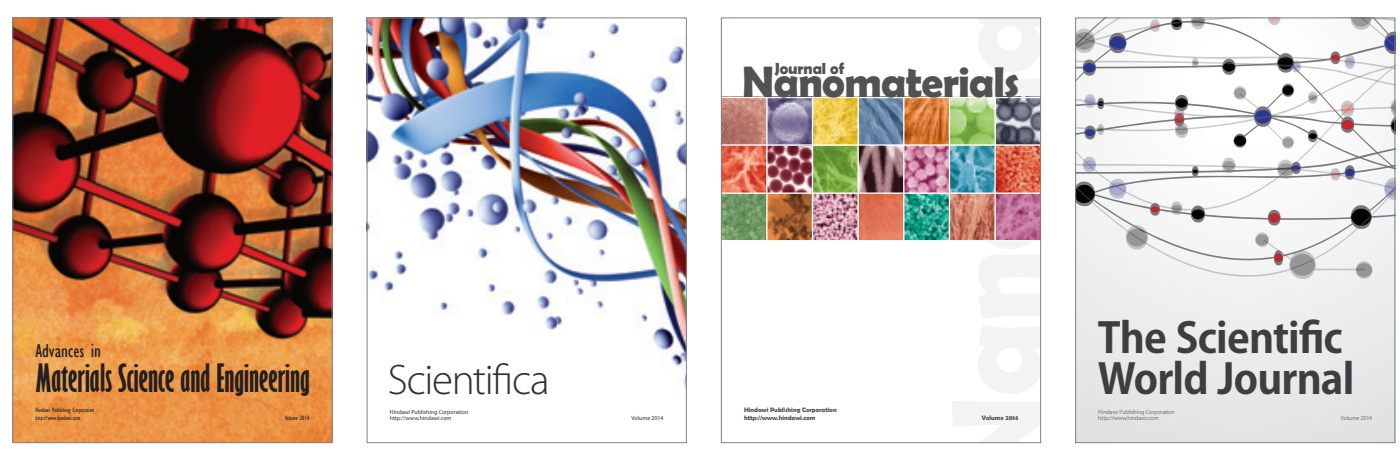

\section{The Scientific World Journal}
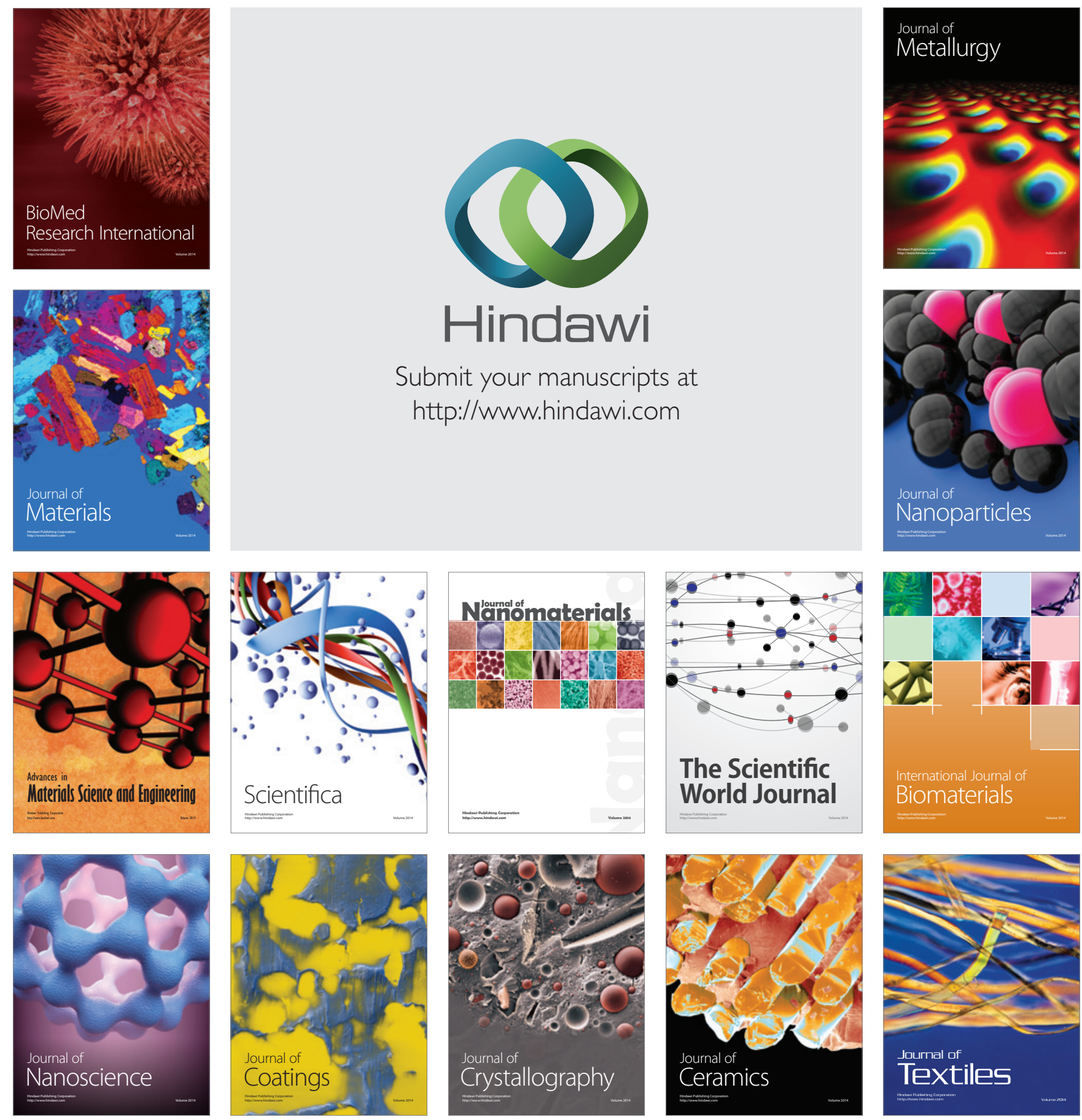